\title{
Endoscopic submucosal dissection of a laterally spreading tumor involving a colonic diverticulum using the counter-traction technique
}

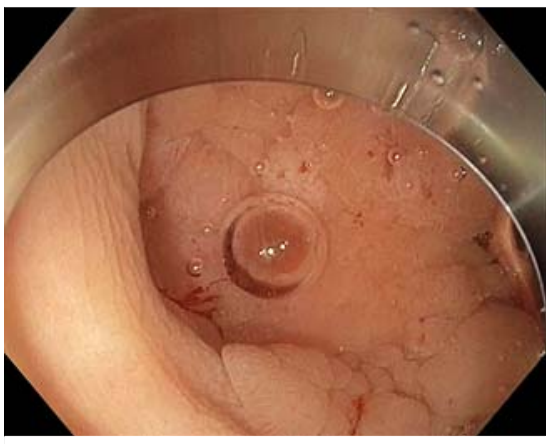

- Fig. 1 Nongranular laterally spreading tumor deeply invading a colonic diverticulum.

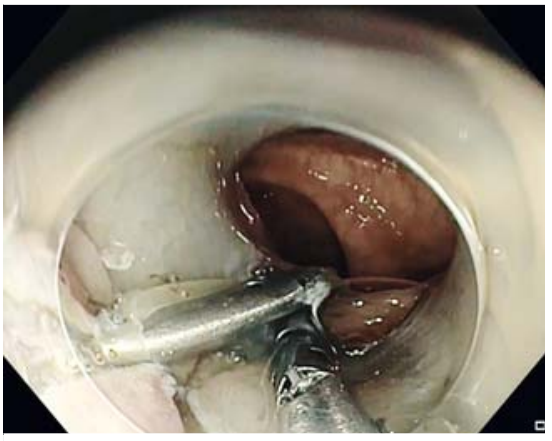

- Fig. 2 Counter-traction of the lesion with clips and rubber band.

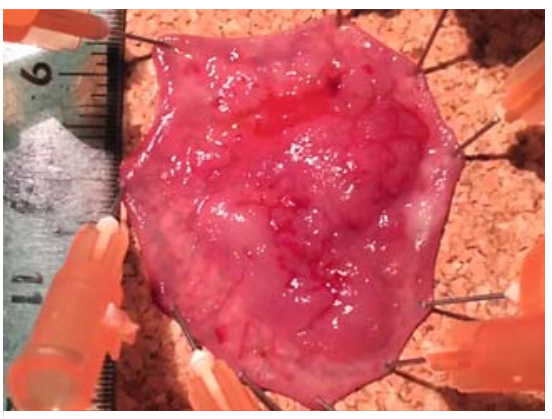

- Fig. 3 The resected piece.

Endoscopic submucosal dissection (ESD) is the technique of choice for the resection of superficial colorectal lesions larger than $20 \mathrm{~mm}$ [1], but the procedure can be technically challenging in some

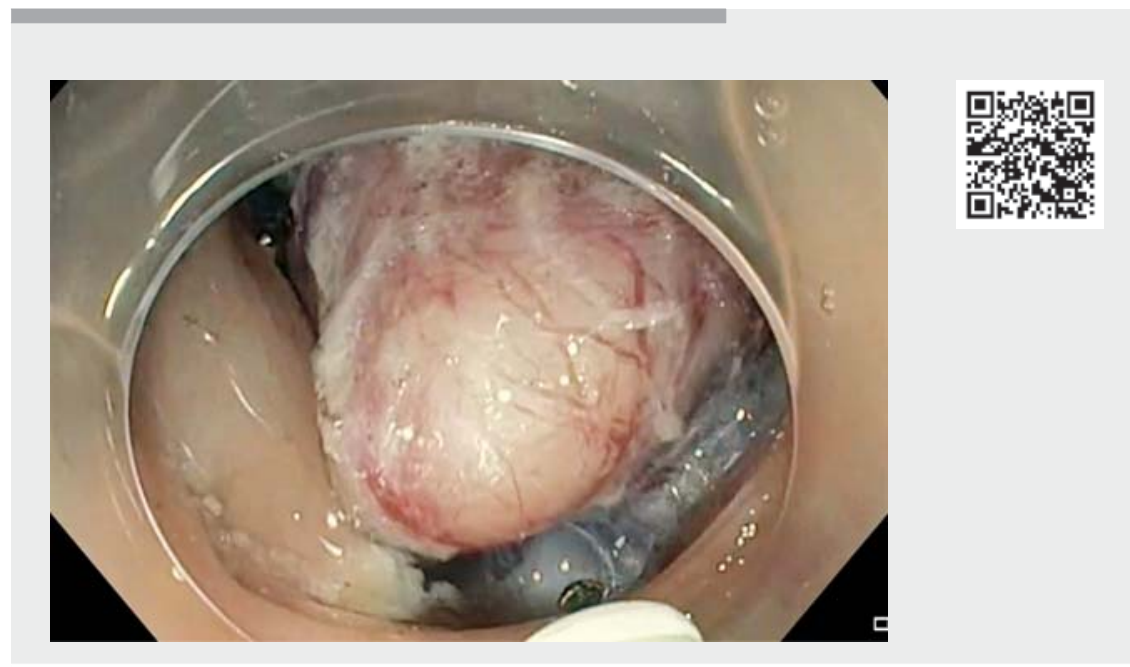

Video 1 Endoscopic submucosal dissection of a laterally spreading tumor involving a colonic diverticulum using the counter-traction technique.

situations. If a lesion involves a diverticulum, there is fear of a higher risk of perforation due to the lack of muscle layer. However, ESD has recently been described as safe and effective in this particular case [2]. Use of a clip and rubber band (counter-traction technique [3]) can help to achieve a satisfying resection with higher technical comfort. This technique has been proved to be effective and safe for resection of neoplastic lesions involving the appendiceal orifice [4]. However, few data are available for lesions involving a diverticulum [5].

We report the case of a $40 \times 30 \mathrm{~mm}$ nongranular laterally spreading tumor (NGLST) deeply invading a colonic diverticulum (Type 3 LST) ( Fig. 1), which was resected with ESD using the countertraction technique ( $\vee$ Video 1$)$.

After submucosal injection around the diverticulum, complete circumferential incision and deep trimming were performed. The first clip grasping a rubber band was fixed at one side of the lesion and a second clip grasping the same rub- ber band was fixed at the opposite colonic wall (> Fig.2). This counter-traction technique allowed better exposition of the submucosae area under the diverticulum, thus strongly facilitating an en bloc resection (\$Fig.3). The ulcer floor of the diverticulum was closed by two clips at the end of the procedure to prevent delayed perforation [2]. The patient was discharged the following day without any adverse events. The histopathology report showed an adenoma with high grade dysplasia and a complete en bloc resection (R0).

This case report, along with others [5], describes the feasibility of ESD with counter-traction method for resection of LSTs deeply invading a diverticulum.

Endoscopy_UCTN_Code_TTT_1AQ_2A]

Competing interests

The authors declare that they have no conflict of interest. 
Thomas Lambin ${ }^{1,2}$, Jérémie Jacques ${ }^{3}$, Jérôme Rivory', Florian Rostain ${ }^{1}$, Timothée Wallenhorst $^{4}$, Mathieu Pioche ${ }^{1,2}$

1 Gastroenterology and Endoscopy Unit, Pavillon L, Edouard Herriot Hospital, Lyon, France

2 Inserm U1032, Labtau, Lyon, France

3 Gastroenterology and Endoscopy Unit, Dupuytren University Hospital, Limoges, France

4 Department of Gastroenterology, Pontchaillou University Hospital, Rennes, France

\section{Corresponding author}

\section{Thomas Lambin, MD}

Endoscopy Unit - Digestive Disease department, Pavillon L - Edouard Herriot Hospital, 69437 Lyon Cedex, France thomaslambin@hotmail.fr
[1] Pimentel-Nunes P, Dinis-Ribeiro M, Ponchon $T$ et al. Endoscopic submucosal dissection: European Society of Gastrointestinal Endoscopy (ESGE) Guideline. Endoscopy 2015; 47 : 829-854

[2] Muramoto T, Ohata K, Sakai E et al. Endoscopic submucosal dissection for colorectal neoplasms in proximity or extending to a diverticulum. Surg Endosc 2020. doi:10.1007/s00464-020-07795-y

[3] Jacques ], Charissoux A, Bordillon P et al. High proficiency of colonic endoscopic submucosal dissection in Europe thanks to countertraction strategy using a double clip and rubber band. Endosc Int Open 2019; 07: E1166-E1174

[4] Oung B, Rivory J, Chabrun E et al. ESD with double clips and rubber band traction of neoplastic lesions developed in the appendiceal orifice is effective and safe. Endosc Int Open 2020; 08: E388-E395

[5] Albouys ], Geyl S, Charissoux A et al. Counter-traction using clips and rubber banding for endoscopic submucosal dissection of a laterally spreading tumor involving a diverticulum in the colon. Endoscopy 2019; 51: E295-E296
Bibliography

Endoscopy 2022; 54: E34-E35

DOI 10.1055/a-1362-9196

ISSN 0013-726X

published online 23.2.2021

(c) 2021. Thieme. All rights reserved.

Georg Thieme Verlag KG, Rüdigerstraße 14 , 70469 Stuttgart, Germany

\section{ENDOSCOPY E-VIDEOS}

https://eref.thieme.de/e-videos

口回 Endoscopy E-Videos is a free access online section, reporting 回: on interesting cases and new techniques in gastroenterological endoscopy. All papers include a high quality video and all contributions are freely accessible online.

This section has its own submission website at https://mc.manuscriptcentral.com/e-videos 